\title{
Review Article \\ Oxidative Stress as a Common Key Event in Developmental Neurotoxicity
}

\author{
Yuhei Nishimura $\mathbb{D}^{1},{ }^{1}$ Yasunari Kanda, ${ }^{2}$ Hideko Sone, ${ }^{3}$ and Hiroaki Aoyama ${ }^{4}$ \\ ${ }^{1}$ Department of Integrative Pharmacology, Mie University Graduate School of Medicine, Tsu, Mie 514-8507, Japan \\ ${ }^{2}$ Division of Pharmacology, National Institute of Health Sciences, Kawasaki, Kanagawa 210-9501, Japan \\ ${ }^{3}$ Yokohama University of Pharmacy, Yokohama, Kanagawa 245-0066, Japan \\ ${ }^{4}$ The Institute of Environmental Toxicology, Joso, Ibaraki 303-0043, Japan \\ Correspondence should be addressed to Yuhei Nishimura; yuhei@med.mie-u.ac.jp
}

Received 29 October 2020; Revised 29 March 2021; Accepted 6 July 2021; Published 20 July 2021

Academic Editor: Ana Cipak Gasparovic

Copyright (c) 2021 Yuhei Nishimura et al. This is an open access article distributed under the Creative Commons Attribution License, which permits unrestricted use, distribution, and reproduction in any medium, provided the original work is properly cited.

\begin{abstract}
The developing brain is extremely sensitive to many chemicals. Perinatal exposure to neurotoxicants has been implicated in several neurodevelopmental disorders, including autism spectrum disorder, attention-deficit hyperactive disorder, and schizophrenia. Studies of the molecular and cellular events related to developmental neurotoxicity have identified a number of "adverse outcome pathways," many of which share oxidative stress as a key event. Oxidative stress occurs when the balance between the production of free oxygen radicals and the activity of the cellular antioxidant system is dysregulated. In this review, we describe some of the developmental neurotoxins that target the antioxidant system and the mechanisms by which they elicit stress, including oxidative phosphorylation in mitochondria and plasma membrane redox system in rodent models. We also discuss future directions for identifying adverse outcome pathways related to oxidative stress and developmental neurotoxicity, with the goal of improving our ability to quickly and accurately screen chemicals for their potential developmental neurotoxicity.
\end{abstract}

\section{Introduction}

The high prevalence of neurodevelopmental disorders such as attention-deficit hyperactive disorder (5.3\%), autism spectrum disorder (1\%), and schizophrenia (1\%) is a source of increasing concern worldwide [1-3]. Many factors can be involved in the etiology of neurodevelopmental disorders, including genetic traits and in utero exposure to environmental contaminants and recreational drugs. Because the developing brain is generally more sensitive than the adult brain to toxicants, exposure to neurotoxic chemicals during development is considered to be a key factor in the prevalence of neurodevelopmental disorders [4-13]. Developmental neurotoxicity (DNT) can result in dysregulation of a range of processes in the brain, including neurogenesis, neuronal differentiation, synaptogenesis, and establishment of functional connectivity networks [7-9, 12]. Several molecular and cellular events leading to DNT, the so-called "adverse outcome pathways," have been identified $[14,15]$. These adverse outcome pathways cover a wide range of molecular initiating events, including inhibition of receptors and enzymes such as $\mathrm{N}$ methyl-D-aspartate receptor and acetylcholinesterase and interruption of biosynthesis and bioavailability of thyroid hormone, which results in adverse outcomes such as impairment of cognitive functions, alteration of sensory functions, and impairment of motor functions [15]. Notably, many of these pathways share oxidative stress (OS) as a key common event associated with neurodevelopmental disorders $[7,8,16$, 17]. In this review, we describe how OS pathways are involved in DNT, describe representative examples of developmental neurotoxins (DTXs) and the mechanisms by which they affect cellular antioxidant and oxidant systems in rodent 
models, and discuss future directions to increase our understanding of adverse outcome pathways as they relate to DNT induced by OS.

\section{The Role of Oxidative Stress in Developmental Neurotoxicity}

OS occurs when reactive oxygen species (ROS) accumulate as a result of an imbalance between the production of ROS and the activity of the cellular antioxidant system $[18,19]$. Superoxide anion $\left(\mathrm{O}_{2}{ }^{-}\right)$, one of the major cellular ROS, is generated as a byproduct of oxidative phosphorylation (OXPHOS) in mitochondria as well as through the activity of nicotinamide adenine dinucleotide phosphate (NADPH) oxidase (NOX) located at the plasma membrane [20, 21]. $\mathrm{O}_{2}{ }^{-}$is converted to hydrogen peroxide $\left(\mathrm{H}_{2} \mathrm{O}_{2}\right)$ and then to oxygen $\left(\mathrm{O}_{2}\right)$ and water $\left(\mathrm{H}_{2} \mathrm{O}\right)$ by enzymatic antioxidants, including superoxide dismutase (SOD), catalase (CAT), and glutathione peroxidase (GPX), and by nonenzymatic antioxidants such as glutathione (GSH). The correct spatiotemporal control of ROS production and activity is crucial to many physiological functions, including neuronal fate and development [22, 23]. However, excessive ROS levels result in damage to DNA, RNA, proteins, and lipids [18]. When this occurs in brain cells, the damage can adversely affect neuronal functions such as memory, learning, and cognition [14]. Various chemicals, both naturally occurring and manmade, can cause DNT through OS $[7,8]$. In the following sections, we describe representative examples of DTXs that cause OS by targeting antioxidant enzymes (Table 1), mitochondria (Table 2), and/or NOX (Table 3).

2.1. DTXs Targeting Antioxidant Enzymes. $\mathrm{O}_{2} \cdot{ }^{-}$and $\mathrm{H}_{2} \mathrm{O}_{2}$ can create hydroxyl radicals that damage DNA, proteins, and lipids when present at aberrantly high levels [24]. $\mathrm{O}_{2}{ }^{-}$ is produced by mitochondrial pathways and/or NOX and is converted to $\mathrm{H}_{2} \mathrm{O}_{2}$ by SOD. In turn, $\mathrm{H}_{2} \mathrm{O}_{2}$ is converted to $\mathrm{O}_{2}$ and $\mathrm{H}_{2} \mathrm{O}$ by CAT in peroxisomes or to $\mathrm{H}_{2} \mathrm{O}$ via the activity of GPX and oxidation of GSH to its disulfide form in the cytosol. Impairment of these antioxidant enzymes thus results in supraphysiological ROS levels that can cause DNT.

Perinatal or postnatal exposure of rodents to lead $(\mathrm{Pb})$ has been shown to reduce the activities of antioxidant enzymes in different brain regions and causes behavioral impairments in the pups [25-28]. The mean blood Pb concentration of rat pups $(5 \mu \mathrm{g} / \mathrm{dL})$ that showed decreased activity of antioxidant enzymes in the brain was equivalent to that of pregnant women who have a significantly high risk of preterm birth ( $\geq 5 \mu \mathrm{g} / \mathrm{dL}$, odds ratio 2 ) [29]. The divalent cation $\mathrm{Pb}^{2+}$ enters the cytosol and mitochondria via calcium ion $\left(\mathrm{Ca}^{2+}\right)$ transporters and replaces other divalent cations such as $\mathrm{Ca}^{2+}$, zinc ion $\left(\mathrm{Zn}^{2+}\right)$, selenium ion $\left(\mathrm{Se}^{2+}\right)$, and iron ion $\left(\mathrm{Fe}^{2+}\right)$, which are essential for the correct structure and activity of many antioxidant enzymes $[24,30-33] . \mathrm{Pb}^{2+}$ also binds with high affinity to sulfhydryl $(\mathrm{SH})$ groups and can inhibit key functional $\mathrm{SH}$ groups in antioxidant enzymes such as SOD, GPX, and CAT [30].

Exposure to methylmercury (MeHg) during early development also causes OS and impairs various neuronal func- tions, especially cerebellar control of movement, as shown in rodents [34]. $\mathrm{MeHg}$ binds with high affinity to both $\mathrm{SH}$ and selenol groups [34] and thus impairs the activities of antioxidant enzymes that require Se for their proper function, including GPX and thioredoxin reductase (TrxR) [24, $34,35]$. Perinatal exposure of mice to $\mathrm{MeHg}$ (5 ppm in drinking water) was shown to decrease TxrR activity in the cerebrum and cerebellum and GPX1 activity in the cerebrum of male, but not female, pups [36]. This sex difference in GSH and Trx metabolism may be related to the higher prevalence of neurodevelopmental disorders among males compared with females in humans [37, 38]. The median blood $\mathrm{Hg}$ concentration of rat pups at birth from dams exposed to $\mathrm{MeHg}$ ( $0.5 \mathrm{ppm}$ in drinking water) during pregnancy was 3.5 and $4.0 \mathrm{mg} / \mathrm{L}$ for males and females, respectively [39]. The decline of differential reinforcement of high rates of behavior occurred sooner in the offspring of rat dams exposed to $\mathrm{MeHg}(0.5 \mathrm{ppm}$ in drinking water) throughout gestation compared to the offspring of dams without $\mathrm{MeHg}$ exposure [40]. The total range of $\mathrm{Hg}$ concentrations in umbilical cord blood in a World Trade Center cohort, a Faroese birth cohort, and a cohort study of congenital Minamata disease was 0.1-63, 0.9-351, and 20-699 $\mu \mathrm{g} / \mathrm{L}$, respectively [41-43]. Higher cord blood $\mathrm{Hg}$ concentration was associated with the decline of the developmental score at 3 and 4 years old [41].

Arsenic (As) is another element that inhibits antioxidant enzyme activity through modification of functional $\mathrm{SH}$ groups [44]. This has been demonstrated in rats, where perinatal exposure of dams to $2-100 \mathrm{mg} / \mathrm{kg} / \mathrm{day}$ As from gestational day (GD) 6 to postnatal day (PND) 21 resulted in impaired SOD, CAT, GPX, and glutathione reductase activities in various brain regions of the pups $[45,46]$. The $50 \%$ lethal dose of As in rats ranges from 15 to $293 \mathrm{mg} / \mathrm{kg}$ [47]. Children with water As levels $>50 \mu \mathrm{g} / \mathrm{L}$ showed significantly low intellectual abilities than children with As levels $<5.5 \mu \mathrm{g} / \mathrm{L}$ in Bangladesh [48]. Mouse pups from dams exposed to As $(55 \mu \mathrm{g} / \mathrm{L}$ in drinking water) during the perinatal period showed learning and memory impairment [49]. The effects of As exposure at these concentrations on the OS in the development of the central nervous system remain to be studied.

The effects of chemicals such as cypermethrin [50], opioids [51], and silver nanoparticles [52] at sublethal doses have been examined in rodents to elucidate the toxicological mechanisms related to OS. Although such concentrations may not be relevant to environmental exposure, the results of these studies suggest that attention should be paid to the consequences of OS after exposure to these chemicals at relatively low doses.

2.2. DTXs Targeting the Mitochondria. OXPHOS is the major cellular pathway of energy production and occurs via the coordinated transfer of electrons through five multisubunit complexes (I-V) located in the inner mitochondrial membrane [24]. Complexes I and II generate electrons through the conversion of nicotinamide adenine dinucleotide from its reduced form (NADH) to its oxidized form (NAD+) and of flavin adenine dinucleotide from its reduced form 
TABLE 1: Developmental neurotoxins targeting antioxidant enzymes.

\begin{tabular}{|c|c|c|c|c|}
\hline Chemical & Exposure, species & $\begin{array}{l}\text { Toxicities on antioxidant enzymes in } \\
\text { the developing brain }\end{array}$ & Other findings in pups & References \\
\hline $\mathrm{Pb}$ & $\begin{array}{l}\text { Pregnant rats were allowed access to } \\
0.1 \% \mathrm{PbAc} \text { in drinking water ad } \\
\text { libitum from GD1 to PND21. Blood } \\
\text { and brain Pb concentrations in the } \\
\text { pups at PND28 were } 5 \mu \mathrm{g} / \mathrm{dL} \text { and } \\
7 \mu \mathrm{g} / \mathrm{g} \text { dry mass, respectively }\end{array}$ & $\begin{array}{c}\text { Both SOD2 and GPx activities were } \\
\text { decreased in FC, HC, and CB on } \\
\text { PND28. Both SOD1 and CAT } \\
\text { activities were decreased in HC on } \\
\text { PND28 }\end{array}$ & $\begin{array}{l}\text { The concentrations of } \mathrm{Se}, \mathrm{Zn}, \mathrm{Cu} \text {, and } \\
\text { Mn were decreased in FC, } \mathrm{HC} \text {, and } \\
\text { CB on PND28 }\end{array}$ & {$[25]$} \\
\hline $\mathrm{Pb}$ & $\begin{array}{c}\text { Pregnant rats were given access to } \\
\text { drinking water containing } 0.2 \% \mathrm{PbAc} \\
\text { from GD5 to PND21. Brain Pb } \\
\text { concentrations at PND21 were } \\
\sim 20 \mu \mathrm{g} / \mathrm{g}\end{array}$ & $\begin{array}{c}\text { Both SOD and GPx activities were } \\
\text { decreased in CB shortly after } \\
\text { exposure }\end{array}$ & $\begin{array}{l}\text { Locomotor activities were impaired } \\
\text { on PD31-33. Purkinje cell densities } \\
\text { were decreased in PD33. } \\
\text { Coadministration of melatonin } \\
\text { alleviated the DNT of Pb }\end{array}$ & {$[26]$} \\
\hline $\mathrm{Pb}$ & $\begin{array}{l}\text { Pregnant rats were given access to } \\
\text { drinking water containing } 0.2 \% \text { PbAc } \\
\text { from GD6 to PND21 }\end{array}$ & $\begin{array}{l}\text { The activities of SOD1, CAT, GPX, } \\
\text { and XO were decreased in both HC } \\
\text { and CB on PND21, 28, 35, and } 60\end{array}$ & $\begin{array}{l}\text { Calcium supplementation } \\
\text { ameliorated the DNT of } \mathrm{Pb}\end{array}$ & [27] \\
\hline $\mathrm{Pb}$ & $\begin{array}{l}\text { Male rats, aged } 4-5 \text { weeks, were } \\
\text { injected IP with } \mathrm{PbAc} \text { at } 10-60 \mathrm{mg} / \mathrm{kg} \\
\text { once daily for } 5 \text { days }\end{array}$ & $\begin{array}{l}\text { SOD activity was decreased in both } \\
\text { FC and HC shortly after exposure }\end{array}$ & $\begin{array}{l}\text { Bax expression and neuronal } \\
\text { apoptosis were increased in FC and } \\
\text { HC shortly after exposure. } \\
\text { Coadministration of t-BHQ } \\
\text { (activator of Nrf2) suppressed the } \\
\text { DNT of Pb }\end{array}$ & {$[28]$} \\
\hline $\mathrm{MeHg}$ & $\begin{array}{l}\text { Pregnant mice were given access to } \\
\text { drinking water containing } 5 \mathrm{ppm} \\
\mathrm{MeHg}(\sim 400 \mu \mathrm{g} / \mathrm{kg} / \text { day }) \text { from } \\
\text { postmating to PND21 }\end{array}$ & $\begin{array}{l}\text { TrxR activity was decreased in both } \\
\text { the cerebrum and CB in male on } \\
\text { PND21. GPx activity was decreased } \\
\text { in the cerebrum in male on PND21 }\end{array}$ & $\begin{array}{l}\text { TrxR and GPx activities in the } \\
\text { cytoplasmic extract of CB were } \\
\text { increased in female on PND21 }\end{array}$ & {$[36]$} \\
\hline As & $\begin{array}{l}\text { Pregnant rats were given access to } \\
\text { drinking water containing As } \\
100 \text { ppm from GD6 to PND21 }\end{array}$ & $\begin{array}{l}\text { The activities of SOD1, SOD2, CAT, } \\
\text { GPX, and GR were decreased in CC, } \\
\text { HC, and CB on PND21, PND28, and } \\
3 \text { months old }\end{array}$ & $\begin{array}{l}\text { Lipid peroxidation and the } \\
\text { expression of caspase- } 3 / 9 \text { mRNA } \\
\text { were increased in CC, HC, and CB on } \\
\text { PND21, PND28, and } 3 \text { months old }\end{array}$ & {$[45]$} \\
\hline As & $\begin{array}{l}\text { Pregnant rats were injected IP with } \\
2-4 \mathrm{mg} / \mathrm{kg} \text { As once daily from GD6 } \\
\text { to PND21 }\end{array}$ & $\begin{array}{l}\text { CAT activity was decreased in FC, } \\
\text { HC, and CS on PND22 and } 45 . \text { SOD } \\
\text { activity was decreased in FC, HC, and } \\
\text { CS on PND22 }\end{array}$ & $\begin{array}{l}\text { Expression of Bax and caspase-3 } \\
\text { proteins was increased in FC, HC, } \\
\text { and CS on PND22 and } 45\end{array}$ & {$[46]$} \\
\hline
\end{tabular}

GD: gestational day; PND: postnatal day; TrxR: thioredoxin reductase; GPX: glutathione peroxidase; SOD: superoxide dismutase; GR: glutathione reductase; FC: frontal cortex; CC: cerebral cortex; HC: hippocampus; CB: cerebellum; CS: corpus striatum; IP: intraperitoneal.

$\left(\mathrm{FADH}_{2}\right)$ to its oxidized form (FAD+). Complex III passes these electrons through coenzyme $\mathrm{Q}$ to cytochrome $\mathrm{c}$. Cytochrome c oxidase (complex IV), which contains two heme groups and two copper atoms, then transfers four electrons to one $\mathrm{O}_{2}$ molecule, resulting in the generation of two $\mathrm{H}_{2} \mathrm{O}$ molecules. Complexes I, III, and IV also pump protons from the mitochondrial matrix into the cristae. Complex $\mathrm{V}$ utilizes these protons to generate adenosine triphosphate (ATP) from adenosine diphosphate (ADP) and inorganic phosphate [24]. $\mathrm{O}_{2} \cdot{ }^{-}$is generated as a byproduct during the transport of electrons to $\mathrm{O}_{2}$. Thus, impairment of the functions of these complexes can thus result in abnormal $\mathrm{O}_{2} \cdot{ }^{-}$production, leading to OS.

Perinatal exposure of rats to As at concentrations that decreased the activities of antioxidant enzymes also resulted in inhibition of complex I, II, III, and IV activities in the frontal cortex, hippocampus, and corpus striatum of the pups [46]. This mechanism is known to be involved in the neurotoxicity of As [53-55]. Another possible mechanism of DNT is that exposure to As may decrease the expression of genes encoding the components of complexes I-V in the brain $[56,57]$.

Similar to the effects of As, perinatal exposure of rats to manganese (Mn) also inhibits complex II activity in the pup striatum, although, unlike the effects of As, complex I activity is increased by $\mathrm{Mn}$ [58]. In this study, the rap pups were intraperitoneally injected with $\mathrm{Mn}(5,10$, or $20 \mathrm{mg} / \mathrm{kg})$ for five consecutive days [58]. In humans, oral ingestion of Mn (about $1.8 \mathrm{mg} / \mathrm{kg}$ ) for 4 weeks caused muscle weaknesses and psychological alterations [59]. The inhibitory effect of Mn on complex II has been demonstrated to selectively occur in mitochondria in the brain, but not the heart or liver, of rats exposed to Mn [60]. However, the mechanism by which Mn affects complex II remains to be elucidated.

The structure of mitochondria is dynamically regulated by fission and fusion [61]. Dynamin-related protein 1 (Drp1) and mitofusin 1 and 2 (Mfn1 and Mfn2) play important roles in mitochondrial fission and fusion, respectively. Drp1 is recruited to the mitochondrial outer membrane, where it oligomerizes and assembles a scission machinery 
TABLE 2: Developmental neurotoxins targeting mitochondria.

\begin{tabular}{|c|c|c|c|c|}
\hline Chemical & Exposure, species & $\begin{array}{l}\text { Toxicities on mitochondria in the } \\
\text { developing brain }\end{array}$ & Other findings in pups & References \\
\hline As & $\begin{array}{l}\text { Pregnant rats were injected IP with } \\
2-4 \mathrm{mg} / \mathrm{kg} \text { As once daily from GD6 } \\
\text { to PND21 }\end{array}$ & $\begin{array}{l}\text { Complex II and III activities were } \\
\text { decreased in FC, HC, and CS on } \\
\text { PND22 and 45. Complex I and IV } \\
\text { activities were decreased in FC, HC, } \\
\text { and CS on PND22 }\end{array}$ & $\begin{array}{l}\text { ROS and MMP were increased } \\
\text { and decreased, respectively, in } \\
\text { FC, HC, and CS on PND22 and } \\
45\end{array}$ & {$[46]$} \\
\hline $\mathrm{Mn}$ & $\begin{array}{l}\text { Pups were injected IP with } \mathrm{MnCl}_{2} \\
\text { (5-20 mg/kg) once daily from } \\
\text { PND8 to PND12 }\end{array}$ & $\begin{array}{l}\text { Complex I and II activities were } \\
\text { increased and decreased, } \\
\text { respectively, in the striatum of the } \\
\text { pups on PND14 }\end{array}$ & $\begin{array}{l}\text { ROS and caspase activity were } \\
\text { increased in the striatum of the } \\
\text { pups on PND14. Abnormalities } \\
\text { in motor coordination were } \\
\text { observed at 3-5 weeks of age }\end{array}$ & {$[58]$} \\
\hline Sevoflurane & $\begin{array}{c}\text { Rats at PND7 were anesthetized } \\
\text { with 3\% sevoflurane in } 40 \% \text { oxygen } \\
\text { for } 4 \mathrm{~h}\end{array}$ & $\begin{array}{l}\text { The protein expression of Drp1 and } \\
\text { Mfn2 was increased and decreased, } \\
\text { respectively, in HC shortly after } \\
\text { exposure }\end{array}$ & $\begin{array}{l}\text { Cleaved caspase-3, cytochrome c, } \\
\text { and apoptosis were increased in } \\
\text { HC shortly after exposure. } \\
\text { Abnormalities in spatial learning } \\
\text { and memory were observed at } \\
\text { PND30 }\end{array}$ & {$[65]$} \\
\hline $\begin{array}{l}\text { General } \\
\text { anesthesia } \\
\text { (midazolam, } \\
\text { isoflurane, and } \\
\text { nitrous oxide) }\end{array}$ & $\begin{array}{l}\text { Rats at PND7 were injected IP with } \\
\text { midazolam }(9 \mathrm{mg} / \mathrm{kg} \text { ) and then } \\
\text { exposed for } 6 \mathrm{~h} \text { to nitrous oxide } \\
\text { (75\%), isoflurane }(0.75 \%) \text {, and } \\
\text { oxygen (approximately } 24 \%)\end{array}$ & $\begin{array}{l}\text { Expression and oligomerization of } \\
\text { Drp1 protein in mitochondria were } \\
\text { increased in subicular and thalamic } \\
\text { regions shortly after exposure }\end{array}$ & $\begin{array}{l}\text { ROS and fission of mitochondria } \\
\text { in the subicular region were } \\
\text { increased shortly after exposure }\end{array}$ & [69] \\
\hline
\end{tabular}

TABle 3: Developmental neurotoxins targeting NADPH oxidase.

\begin{tabular}{|c|c|c|c|c|}
\hline Chemical & Exposure, species & $\begin{array}{l}\text { Toxicities on NOX in the } \\
\text { developing brain }\end{array}$ & Other findings in pups & References \\
\hline Sevoflurane & $\begin{array}{c}\text { Mouse pups at PND6 were } \\
\text { anesthetized with } 3 \% \\
\text { sevoflurane in } 40 \% \text { oxygen for } \\
6 \mathrm{~h}\end{array}$ & $\begin{array}{c}\text { p22phox protein expression was } \\
\text { increased in the brain shortly after } \\
\text { exposure }\end{array}$ & $\begin{array}{l}\text { ROS, cytochrome c, and cleaved caspase- } \\
3 \text { were increased in the brain shortly after } \\
\text { exposure. Abnormal freezing behavior } \\
\text { was observed at } 11-13 \text { weeks of age. } \\
\text { These toxicities were suppressed by } \\
\text { cotreatment with the NOX inhibitor }\end{array}$ & [78] \\
\hline Sevoflurane & $\begin{array}{c}\text { Mouse pups were } \\
\text { anesthetized with } 3 \% \\
\text { sevoflurane in } 40 \% \text { oxygen for } \\
\text { 2h daily from PND6 to PND8 }\end{array}$ & $\begin{array}{c}\text { NOX2 protein expression was } \\
\text { increased in FC and HC shortly after } \\
\text { exposure }\end{array}$ & $\begin{array}{l}\text { Apoptosis was increased in the brain } \\
\text { shortly after exposure. Abnormal } \\
\text { freezing behavior and the impairments of } \\
\text { spatial learning and memory were } \\
\text { observed at } 9 \text {-11 weeks of age }\end{array}$ & [77] \\
\hline Ethanol & $\begin{array}{l}\text { Pregnant mice at GD8 were } \\
\text { injected IP with ethanol } \\
\qquad(12 \mathrm{~g} / \mathrm{kg})\end{array}$ & $\begin{array}{l}\text { The mRNA expressions of Duox } 2 \\
\text { Noxa1, and Noxo1 were increased in } \\
\text { the brains on GD18 }\end{array}$ & $\begin{array}{l}\text { The mRNA expressions of Noxa1 and } \\
\text { p67phox were increased in the placenta } \\
\text { and liver, respectively, on GD18 }\end{array}$ & {$[81]$} \\
\hline Ethanol & $\begin{array}{l}\text { Pregnant mice at GD9 were } \\
\text { injected IP with ethanol } \\
(2.9 \mathrm{~g} / \mathrm{kg})\end{array}$ & $\begin{array}{l}\text { The mRNA expressions of Duox1, } \\
\text { Noxa1, Noxo1, p22phox, p67phox, } \\
\text { and Rac1 were increased in the brains } \\
\text { shortly after exposure }\end{array}$ & $\begin{array}{l}\text { NOX activity, ROS generation, oxidative } \\
\text { DNA damage, and apoptosis were } \\
\text { increased in the brains shortly after } \\
\text { exposure. These toxicities were } \\
\text { suppressed by cotreatment with the NOX } \\
\text { inhibitor }\end{array}$ & {$[82]$} \\
\hline
\end{tabular}

GD: gestational day; PND: postnatal day; FC: frontal cortex; HC: hippocampus; IP: intraperitoneal.

that enables organelle constriction and cleavage. Mfn1 and Mfn2 are located at the mitochondrial outer membrane and, together with optic atrophy 1 (Opa1) located in the inner mitochondrial membrane, mediate the stepwise events that result in mitochondrial fusion. Mitochondrial fission can be triggered by various stimuli, including 1-methyl-4-phenylpyridinium and isoniazid, which affect the mitochondrial membrane potential $[62,63]$. Aberrant stimulation of mitochondrial fission and fusion creates a deleterious cycle resulting in excessive ROS production [64]. 
A number of exogenous chemicals have been shown to modulate mitochondrial dynamics in the developing rodent brain. Postnatal exposure of rodent pups to the inhalation anesthetic sevoflurane increases and decreases the expression of Drp1 and Mfn2, respectively, in the hippocampus [65] and additionally increases the expression of cyclophilin $\mathrm{D}$, a factor that modulates the mitochondrial permeability transition pore [66]. The concentration of sevoflurane used in these rodent studies (3\%), which did not induce significant disturbances in ventilation, blood oxygenation, or cerebrospinal fluid content in mice [67], is similar to the minimum alveolar concentration of sevoflurane used for anesthesia in children (2.0-3.3\%) [68]. Postnatal exposure of rat pups to general anesthesia, composed of midazolam, isoflurane, and nitrous oxide, increases the expression and oligomerization of Drp1 at the mitochondria to promote fission in the subicular region of the pup brain [69] and additionally increases mitochondrial membrane permeability [70]. The concentration of isoflurane used in the rat study $(0.75 \%)$ is similar to those that caused isoflurane-induced neuroapoptosis in the neonatal rhesus macaque brain (0.7-1.5\%) [71]. These results suggest that changes in mitochondrial membrane permeability may be involved in the mechanism for the anesthesia-induced enhancement of mitochondrial fission in the developing brain. In addition to the in vivo studies, Mfn has been reported to mediate neural differentiation from human induced pluripotent stem cells, which are commonly used for DNT evaluation in vitro [72, 73]. Several DTXs, including tributyltin and 5-fluorouracil, have been reported to induce degradation of Mfn protein and subsequently inhibit neural differentiation $[72,74]$. Thus, it would be useful to include examination of mitochondrial dynamics in the evaluation of DTXs in vivo and in vitro.

2.3. DTXs Targeting NOX. The NOX family of enzymes is located on the plasma membrane and is an important source of ROS, especially $\mathrm{O}_{2} \cdot{ }^{-}[75,76]$. The human NOX protein family consists of seven homologs: NOX1, NOX2, NOX3, NOX4, NOX5, DUOX1, and DUOX2. NOX1, NOX2, and NOX3 interact with p22phox, a transmembrane protein, and act as a scaffold and binding platform for the cytosolic activators Noxo1, Noxa1, p47phox, p67phox, and Rac [75]. DUOX1 and DUOX2 require binding to Duoxal and Duoxa2, respectively, to exert their activities.

Postnatal exposure of mouse pups to sevoflurane increases the expression of NOX2 [77] and p22phox [78], resulting in OS and apoptosis in the brains. Notably, these experiments were performed with sevoflurane concentrations (3\%) comparable to those used for anesthesia in children (2.0-3.3\%) [68]. In the mouse experiments, the effects were ameliorated by coadministration of the NOX inhibitor apocynin [78] or curcumin [77], suggesting that sevoflurane-induced OS in the developing brain is caused by activation of NOX, at least in part [79]. Further work will be needed to fully understand the mechanisms by which sevoflurane activates NOX.

Exposure of the fetus to ethanol has a profound effect on the developing brain; indeed, OS resulting from prenatal exposure to ethanol is a key pathogenic factor in fetal alcohol syndrome [80]. Prenatal exposure of mice to ethanol increases brain expression of various NOX subunits, including p22phox, Noxa1, Noxo1, p67phox, and Rac1 [81, 82]. In these studies, the pregnant mice were intraperitoneally injected with ethanol at GD8 $(12 \mathrm{~g} / \mathrm{kg})$ [81] or GD9 $(2.9 \mathrm{~g} / \mathrm{kg})$ [82]. In primates, the majority of studies on fetal alcohol syndrome utilize oral intubation of ethanol (0.3$5.0 \mathrm{~g} / \mathrm{kg}$ ) once-weekly [83]. In vitro studies with the human neuroblastoma cell line SH-SY5Y showed that ethanol increases ROS production by inducing p47phox [84]. Of note, dominant negative inhibition of Cdc42 suppressed the induction of p47phox in SH-SY5Y cells, suggesting a potential role for Cdc42 in the effects of ethanol on NOX activity in the brain [84]. Nevertheless, the exact mechanisms by which ethanol exposure increases OS in the developing brain remain to be fully elucidated.

\section{Future Directions}

Supraphysiological intracellular levels of ROS can be generated through a number of mechanisms, including alterations in the balance between antioxidant and oxidant systems, perturbation of mitochondrial dynamics, and activation of NOX activity at the plasma membrane. As described here, excessive ROS levels negatively affect crucial neuronal functions in the developing brain that impact both neurodevelopmental and neurobehavioral pathways.

In this review, we mainly focused on studies that employed rodent models to examine DNT related to OS. In extrapolating the results to humans, however, it should be noted that several relevant species differences exist, including the structures and functions of the placenta $[85,86]$ and brain $[87,88]$. For example, human placenta is hemomonochorial and includes a single syncytiotrophoblast zone, whereas mouse placenta is hemotrichorial and consists of a trophoblast giant cell layer, spongiotrophoblast layer, and labyrinthine layer [85]. Additionally, human placenta, but not mouse placenta, contains an aromatase enabling the synthesis of estrogen [86]. The major growth spurt of the brain occurs at different stages in humans and rats, namely, at the prenatal and postnatal stages, respectively [88]. Various human testing platforms, such as placenta-on-a-chip and the ex vivo placenta perfusion model, as well as brain microphysiological systems, have been developed to more precisely assess DNT of chemicals in humans $[15,85,89,90]$. The difference of DNT between prenatal and postnatal exposure in human should also be carefully examined [91].

The upstream and downstream events resulting in and from abnormal ROS levels can be investigated in vitro using neuronal cells that differentiated from embryonic stem cells or induced pluripotent stem cells [72, 74, 92, 93]. Studies using human neural stem cells, for example, have revealed that rotenone, an inhibitor of mitochondrial complex I, activates the Nrf2 pathway in response to OS and that activation of this pathway could be used as a readout to assess neurotoxicity [94]. These experimental systems enable testing of the major neurodevelopmental endpoints included in a DNT testing battery [73]. 
Alternative in vivo testing methods that employ fish, which are commonly used to examine morphological and behavioral effects, can be employed to assess DNT mediated by OS [95-98]. In one example, developmental exposure of zebrafish to endosulfan, a fat-soluble organochlorine pesticide, caused morphological defects and abnormal behavior that was suppressed by coexposure to vitamin E, a fatsoluble antioxidant, suggesting that OS was a key event in endosulfan neurotoxicity [99]. Several zebrafish behaviors have also been used as alternative phenotypes of neurodevelopmental disorders in humans $[95,100]$.

Neuroinflammation is closely related to OS and associated with neurodevelopmental disorders [101-104]. Supraphysiological intracellular levels of ROS induce the production of proinflammatory cytokines from astrocytes and microglia [101, 104]. These cytokines activate NOX of astrocytes and microglia, resulting in a vicious cycle of OS and neuroinflammation $[103,105]$. The neuroinflammation may lead to neuronal apoptosis and alterations of homeostatic levels of neurotransmitters [102, 104]. Neuroinflammation can be assessed in rodents [106], zebrafish [107], and pluripotent stem cells [108].

Various omics technologies are powerful strategies to identify adverse outcome pathways [109-114]. For example, integration of cell-based high-throughput screening, cell lysate microarray immunostaining, and transcriptome analysis successfully identified OS as a key common adverse outcome pathway in nanomaterial-induced fibrosis and cancer [115]. In silico analysis also provides useful information about the pharmacokinetics of chemicals that cause OS [116] as well as their ability to induce ROS $[117,118]$ and their quantitative structure-activity relationships [119]. Integration of in silico, in vitro, and/or in vivo studies will also facilitate prediction of the toxicities of OSrelated chemicals [120-123].

Integration of these approaches will not only enhance our understanding of OS-related DNT and the relationship between dysregulated OS and the pathogenesis of neurodevelopmental disorders but also expand our ability to quickly and accurately screen chemicals for their potential DNT properties.

\section{Conflicts of Interest}

The authors declare that there are no conflicts of interest regarding the publication of this article.

\section{Acknowledgments}

We thank Anne M. O'Rourke, PhD, from Edanz Group (https://en-author-services.edanzgroup.com/ac) for editing the draft of this manuscript. This work was supported in part by the Long-range Research Initiative of the Japan Chemical Industrial Association (20-3-08 to YN), the Japan Society for the Promotion of Science KAKENHI (19K07318 to YN), and the Health and Labour Sciences Research Grant from the Ministry of Health, Labour, and Welfare, Japan (19KD1003 to $\mathrm{YK})$.

\section{References}

[1] J. Posner, G. V. Polanczyk, and E. Sonuga-Barke, "Attentiondeficit hyperactivity disorder," The Lancet, vol. 395, pp. 450462,2020

[2] M. C. Lai, M. V. Lombardo, and S. Baron-Cohen, "Autism," Lancet, vol. 383, pp. 896-910, 2014.

[3] M. J. Owen, A. Sawa, and P. B. Mortensen, "Schizophrenia," Lancet, vol. 388, pp. 86-97, 2016.

[4] H. Aoyama, "Developmental neurotoxicity testing: scientific approaches towards the next generation to protect the developing nervous system of children. An overview of the Developmental Neurotoxicity Symposium in 2011," Congenital anomalies, vol. 52, pp. 119-121, 2012.

[5] K. Lyall, R. J. Schmidt, and I. Hertz-Picciotto, "Maternal lifestyle and environmental risk factors for autism spectrum disorders," International journal of epidemiology, vol. 43, no. 2, pp. 443-464, 2014.

[6] H. Aoyama, N. Takahashi, Y. Shutoh, A. Motomura, and K. Crofton, "Developmental neurotoxicology: history and outline of developmental neurotoxicity study guidelines," Food Safety, vol. 3, pp. 48-61, 2015.

[7] D. B. Heyer and R. M. Meredith, "Environmental toxicology: sensitive periods of development and neurodevelopmental disorders," Neurotoxicology, vol. 58, pp. 23-41, 2017.

[8] K. D. Rock and H. B. Patisaul, "Environmental mechanisms of neurodevelopmental toxicity," Current environmental health reports, vol. 5, no. 1, pp. 145-157, 2018.

[9] N. Cattane, J. Richetto, and A. Cattaneo, "Prenatal exposure to environmental insults and enhanced risk of developing schizophrenia and autism spectrum disorder: focus on biological pathways and epigenetic mechanisms," Neuroscience \& Biobehavioral Reviews, vol. 117, pp. 253-278, 2020.

[10] K. E. Pelch, A. L. Bolden, and C. F. Kwiatkowski, "Environmental chemicals and autism: a scoping review of the human and animal research," Environmental health perspectives, vol. 127, article 46001, 2019.

[11] S. Bölte, S. Girdler, and P. B. Marschik, "The contribution of environmental exposure to the etiology of autism spectrum disorder," Cellular and Molecular Life Sciences, vol. 76, no. 7, pp. 1275-1297, 2019.

[12] J. A. Hollander, D. A. Cory-Slechta, F. N. Jacka et al., "Beyond the looking glass: recent advances in understanding the impact of environmental exposures on neuropsychiatric disease," Neuropsychopharmacology, vol. 45, no. 7, pp. 1086-1096, 2020.

[13] T. Carlsson, F. Molander, M. J. Taylor, U. Jonsson, and S. Bölte, "Early environmental risk factors for neurodevelopmental disorders - a systematic review of twin and sibling studies," Development and Psychopathology, pp. 1-48, 2020.

[14] N. Spinu, A. Bal-Price, M. T. D. Cronin, S. J. Enoch, J. C. Madden, and A. P. Worth, "Development and analysis of an adverse outcome pathway network for human neurotoxicity," Archives of toxicology, vol. 93, no. 10, pp. 2759-2772, 2019.

[15] J. Li, R. Settivari, M. J. LeBaron, and M. S. Marty, “An industry perspective: a streamlined screening strategy using alternative models for chemical assessment of developmental neurotoxicity," Neurotoxicology, vol. 73, pp. 17-30, 2019.

[16] K. K. Griffiths and R. J. Levy, "Evidence of mitochondrial dysfunction in autism: biochemical links, genetic-based 
associations, and non-energy-related mechanisms," Oxidative medicine and cellular longevity, vol. 2017, Article ID 4314025, 12 pages, 2017.

[17] F. E. Emiliani, T. W. Sedlak, and A. Sawa, "Oxidative stress and schizophrenia: recent breakthroughs from an old story," Current opinion in psychiatry, vol. 27, no. 3, pp. 185-190, 2014.

[18] M. Schieber and N. S. Chandel, "ROS function in redox signaling and oxidative stress," Current biology, vol. 24, no. 10, pp. R453-R462, 2014.

[19] C. L. Bigarella, R. Liang, and S. Ghaffari, "Stem cells and the impact of ROS signaling," Development, vol. 141, pp. 42064218,2014

[20] F. Jiang, Y. Zhang, and G. J. Dusting, "NADPH oxidasemediated redox signaling: roles in cellular stress response, stress tolerance, and tissue repair," Pharmacological reviews, vol. 63 , pp. $218-242,2011$.

[21] A. Terzi and D. M. Suter, "The role of NADPH oxidases in neuronal development," Free Radical Biology and Medicine, vol. 154, pp. 33-47, 2020.

[22] K. A. Kennedy, S. D. Sandiford, I. S. Skerjanc, and S. S. Li, "Reactive oxygen species and the neuronal fate," Cellular and Molecular Life Sciences, vol. 69, pp. 215-221, 2012.

[23] C. Wilson, E. Muñoz-Palma, and C. González-Billault, "From birth to death: a role for reactive oxygen species in neuronal development," Seminars in cell \& developmental biology, vol. 80, pp. 43-49, 2018.

[24] S. W. Caito and M. Aschner, "Mitochondrial redox dysfunction and environmental exposures," Antioxidants \& redox signaling, vol. 23, pp. 578-595, 2015.

[25] I. Baranowska-Bosiacka, I. Gutowska, M. Marchlewicz et al., "Disrupted pro- and antioxidative balance as a mechanism of neurotoxicity induced by perinatal exposure to lead," Brain research, vol. 1435, pp. 56-71, 2012.

[26] M. Bazrgar, I. Goudarzi, T. Lashkarbolouki, and M. Elahdadi Salmani, "Melatonin ameliorates oxidative damage induced by maternal lead exposure in rat pups," Physiology \& behavior, vol. 151, pp. 178-188, 2015.

[27] R. R. Gottipolu and C. B. Davuljigari, "Perinatal exposure to lead: reduction in alterations of brain mitochondrial antioxidant system with calcium supplement," Biological Trace Element Research, vol. 162, pp. 270-277, 2014.

[28] F. Ye, X. Li, L. Li, J. Yuan, and J. Chen, "t-BHQ provides protection against lead neurotoxicity via Nrf2/HO-1 pathway," Oxidative Medicine and Cellular Longevity, vol. 2016, Article ID 2075915, 15 pages, 2016.

[29] C. Taylor, J. Golding, and A. Emond, "Adverse effects of maternal lead levels on birth outcomes in the ALSPAC study: a prospective birth cohort study," BJOG: An International Journal of Obstetrics \& Gynaecology, vol. 122, pp. 322-328, 2015.

[30] P. C. Hsu and Y. L. Guo, "Antioxidant nutrients and lead toxicity," Toxicology, vol. 180, pp. 33-44, 2002.

[31] T. I. Lidsky and J. S. Schneider, "Lead neurotoxicity in children: basic mechanisms and clinical correlates," Brain, vol. 126, pp. 5-19, 2003.

[32] J. M. Ordemann and R. N. Austin, "Lead neurotoxicity: exploring the potential impact of lead substitution in zinc-finger proteins on mental health," Metallomics, vol. 8, pp. 579-588, 2016.
[33] R. Gorkhali, K. Huang, M. Kirberger, and J. J. Yang, "Defining potential roles of $\mathrm{Pb} 2+$ in neurotoxicity from a calciomics approach," Metallomics, vol. 8, pp. 563-578, 2016.

[34] E. Patel and M. Reynolds, "Methylmercury impairs motor function in early development and induces oxidative stress in cerebellar granule cells," Toxicology Letters, vol. 222, pp. 265-272, 2013.

[35] V. Branco and C. Carvalho, "The thioredoxin system as a target for mercury compounds," Biochimica et Biophysica Acta (BBA)-General Subjects, vol. 1863, article 129255, 2019.

[36] J. A. Ruszkiewicz, A. B. Bowman, M. Farina, J. B. T. Rocha, and M. Aschner, "Sex- and structure-specific differences in antioxidant responses to methylmercury during early development," Neurotoxicology, vol. 56, pp. 118-126, 2016.

[37] L. Wang, Y. J. Ahn, and R. Asmis, "Sexual dimorphism in glutathione metabolism and glutathione-dependent responses," Redox biology, vol. 31, article 101410, 2020.

[38] A. S. Monte, F. E. da Silva, C. N. Lima et al., "Sex influences in the preventive effects of $\mathrm{N}$-acetylcysteine in a two-hit animal model of schizophrenia," Journal of Psychopharmacology, vol. 34, pp. 125-136, 2020.

[39] M. C. Newland and P. A. Reile, "Blood and brain mercury levels after chronic gestational exposure to methylmercury in rats," Toxicological sciences, vol. 50, pp. 106-116, 1999.

[40] M. C. Newland and E. B. Rasmussen, "Aging unmasks adverse effects of gestational exposure to methylmercury in rats," Neurotoxicology and teratology, vol. 22, pp. 819-828, 2000.

[41] S. A. Lederman, R. L. Jones, K. L. Caldwell et al., "Relation between cord blood mercury levels and early child development in a World Trade Center cohort," Environmental health perspectives, vol. 116, pp. 1085-1091, 2008.

[42] P. Grandjean, E. Budtz-Jørgensen, P. J. Jørgensen, and P. Weihe, "Umbilical cord mercury concentration as biomarker of prenatal exposure to methylmercury," Environmental health perspectives, vol. 113, pp. 905-908, 2005.

[43] H. Akagi, P. Grandjean, Y. Takizawa, and P. Weihe, "Methylmercury dose estimation from umbilical cord concentrations in patients with Minamata disease," Environmental Research, vol. 77, pp. 98-103, 1998.

[44] A. De Vizcaya-Ruiz, O. Barbier, R. Ruiz-Ramos, and M. E. Cebrian, "Biomarkers of oxidative stress and damage in human populations exposed to arsenic," Mutation Research/Genetic Toxicology and Environmental Mutagenesis, vol. 674, pp. 85-92, 2009.

[45] P. K. Kadeyala, S. Sannadi, and R. R. Gottipolu, "Alterations in apoptotic caspases and antioxidant enzymes in arsenic exposed rat brain regions: reversal effect of essential metals and a chelating agent," Environmental toxicology and pharmacology, vol. 36, pp. 1150-1166, 2013.

[46] L. P. Chandravanshi, R. Gupta, and R. K. Shukla, "Developmental neurotoxicity of arsenic: involvement of oxidative stress and mitochondrial functions," Biological Trace Element Research, vol. 186, pp. 185-198, 2018.

[47] PHECf Radiation, Arsenic: toxicological overview, 2016.

[48] G. A. Wasserman, X. Liu, F. Parvez et al., "Water arsenic exposure and children's intellectual function in Araihazar, Bangladesh," Environmental health perspectives, vol. 112, pp. 1329-1333, 2004.

[49] E. J. Martinez-Finley, A. M. Ali, and A. M. Allan, "Learning deficits in C57BL/6J mice following perinatal arsenic 
exposure: consequence of lower corticosterone receptor levels?," Pharmacology Biochemistry and Behavior, vol. 94, pp. 271-277, 2009.

[50] O. K. Afolabi, F. A. Aderibigbe, D. T. Folarin, A. Arinola, and A. D. Wusu, "Oxidative stress and inflammation following sub-lethal oral exposure of cypermethrin in rats: mitigating potential of epicatechin," Heliyon, vol. 5, article e02274l, 2019.

[51] S. K. Yadav, D. Kumar, P. Kumar, P. K. Gupta, and R. Bhattacharya, "Biochemical, oxidative, and physiological changes caused by acute exposure of fentanyl and its 3 analogs in rodents," International Journal of Toxicology, vol. 37, pp. 28-37, 2018.

[52] B.-H. Mao, Z.-Y. Chen, Y.-J. Wang, and S.-J. Yan, "Silver nanoparticles have lethal and sublethal adverse effects on development and longevity by inducing ROS-mediated stress responses," Scientific reports, vol. 8, pp. 1-16, 2018.

[53] N. Dwivedi, A. Mehta, A. Yadav, B. K. Binukumar, K. D. Gill, and S. J. S. Flora, "MiADMSA reverses impaired mitochondrial energy metabolism and neuronal apoptotic cell death after arsenic exposure in rats," Toxicology and Applied Pharmacology, vol. 256, pp. 241-248, 2011.

[54] P. Srivastava, R. S. Yadav, L. P. Chandravanshi et al., "Unraveling the mechanism of neuroprotection of curcumin in arsenic induced cholinergic dysfunctions in rats," Toxicology and Applied Pharmacology, vol. 279, pp. 428-440, 2014.

[55] C. Prakash, M. Soni, and V. Kumar, "Mitochondrial oxidative stress and dysfunction in arsenic neurotoxicity: a review," Journal of Applied Toxicology, vol. 36, pp. 179-188, 2016.

[56] Y. Hong, F. Piao, Y. Zhao, S. Li, Y. Wang, and P. Liu, "Subchronic exposure to arsenic decreased Sdha expression in the brain of mice," Neurotoxicology, vol. 30, pp. 538-543, 2009.

[57] C. Prakash and V. Kumar, "Arsenic-induced mitochondrial oxidative damage is mediated by decreased PGC- $1 \alpha$ expression and its downstream targets in rat brain," Chemico-biological interactions, vol. 256, pp. 228-235, 2016.

[58] F. M. Cordova, A. S. Aguiar Jr., T. V. Peres et al., "In vivo manganese exposure modulates Erk, Akt and Darpp-32 in the striatum of developing rats, and impairs their motor function," PLoS One, vol. 7, article e33057l, 2012.

[59] M. Holzgraefe, W. Poser, H. Kijewski, and W. Beuche, "Chronic enteral poisoning caused by potassium permanganate: a case report," Journal of Toxicology, vol. 24, 244 pages, 1986.

[60] T. E. Gunter, B. Gerstner, T. Lester et al., "An analysis of the effects of $\mathrm{Mn} 2+$ on oxidative phosphorylation in liver, brain, and heart mitochondria using state 3 oxidation rate assays," Toxicology and applied pharmacology, vol. 249, pp. 65-75, 2010.

[61] H. Hagberg, C. Mallard, C. I. Rousset, and C. Thornton, "Mitochondria: hub of injury responses in the developing brain," The Lancet Neurology, vol. 13, pp. 217-232, 2014.

[62] X. Wang, B. Su, W. Liu et al., "DLP1-dependent mitochondrial fragmentation mediates 1-methyl-4-phenylpyridinium toxicity in neurons: implications for Parkinson's disease," Aging Cell, vol. 10, pp. 807-823, 2011.

[63] T. Zhang, T. Ikejima, L. Li et al., "Impairment of mitochondrial biogenesis and dynamics involved in isoniazid-induced apoptosis of HepG2 cells was alleviated by p38 MAPK pathway," Frontiers in Pharmacology, vol. 8, 2017.
[64] J. Ježek, K. F. Cooper, and R. Strich, "Reactive oxygen species and mitochondrial dynamics: the yin and yang of mitochondrial dysfunction and cancer progression," Antioxidants, vol. 7, 2018.

[65] F. Yang, Y. Shan, Z. Tang et al., "The neuroprotective effect of hemin and the related mechanism in sevoflurane exposed neonatal rats," Frontiers in Neuroscience, vol. 13, 2019.

[66] Y. Zhang, P. Lu, F. Liang et al., "Cyclophilin D contributes to anesthesia neurotoxicity in the developing brain," Frontiers in cell and developmental biology, vol. 7, p. 396, 2019.

[67] M. Satomoto, Y. Satoh, K. Terui et al., "Neonatal exposure to sevoflurane induces abnormal social behaviors and deficits in fear conditioning in mice," Anesthesiology, vol. 110, pp. 628637, 2009.

[68] J. Lerman, N. Sikich, S. Kleinman, and S. Yentis, "The pharmacology of sevoflurane in infants and children," Anesthesiology, vol. 80, pp. 814-824, 1994.

[69] A. Boscolo, D. Milanovic, J. A. Starr et al., "Early exposure to general anesthesia disturbs mitochondrial fission and fusion in the developing rat brain," Anesthesiology, vol. 118, pp. 1086-1097, 2013.

[70] V. Jevtovic-Todorovic, "Exposure of developing brain to general anesthesia: what is the animal evidence?," Anesthesiology, vol. 128, pp. 832-839, 2018.

[71] A. M. Brambrink, A. S. Evers, M. S. Avidan et al., "Isofluraneinduced neuroapoptosis in the neonatal rhesus macaque brain," Anesthesiology, vol. 112, pp. 834-841, 2010.

[72] S. Yamada, Y. Kubo, D. Yamazaki et al., "Tributyltin inhibits neural induction of human induced pluripotent stem cells," Scientific reports, vol. 8, no. 1, article 12155, 2018.

[73] E. Fritsche, M. Barenys, J. Klose et al., "Development of the concept for stem cell-based developmental neurotoxicity evaluation," Toxicological Sciences, vol. 165, pp. 14-20, 2018.

[74] S. Yamada, D. Yamazaki, and Y. Kanda, "5-Fluorouracil inhibits neural differentiation via Mfn1/2 reduction in human induced pluripotent stem cells," The Journal of toxicological sciences, vol. 43, pp. 727-734, 2018.

[75] R. P. Brandes, N. Weissmann, and K. Schröder, "Nox family NADPH oxidases: molecular mechanisms of activation," Free Radical Biology and Medicine, vol. 76, pp. 208-226, 2014.

[76] D. E. Nordzieke and I. Medraño-Fernandez, "The plasma membrane: a platform for intra- and intercellular redox signaling," Antioxidants, vol. 7, 2018.

[77] M. H. Ji, L. L. Qiu, J. J. Yang et al., "Pre-administration of curcumin prevents neonatal sevoflurane exposure-induced neurobehavioral abnormalities in mice," Neurotoxicology, vol. 46, pp. 155-164, 2015.

[78] Z. Sun, M. Satomoto, Y. U. Adachi, H. Kinoshita, and K. Makita, "Inhibiting NADPH oxidase protects against long-term memory impairment induced by neonatal sevoflurane exposure in mice," BJA: British Journal of Anaesthesia, vol. 117, pp. 80-86, 2016.

[79] S. C. Johnson, A. Pan, L. Li, M. Sedensky, and P. Morgan, "Neurotoxicity of anesthetics: mechanisms and meaning from mouse intervention studies," Neurotoxicology and teratology, vol. 71, pp. 22-31, 2019.

[80] X. Joya, O. Garcia-Algar, J. Salat-Batlle, C. Pujades, and O. Vall, "Advances in the development of novel antioxidant therapies as an approach for fetal alcohol syndrome prevention," Birth Defects Research Part A: Clinical and Molecular Teratology, vol. 103, pp. 163-177, 2015. 
[81] A. J. Hill, N. Drever, H. Yin, E. Tamayo, G. Saade, and E. Bytautiene, "The role of NADPH oxidase in a mouse model of fetal alcohol syndrome," American journal of obstetrics and gynecology, vol. 210, p. 466.e461, 2014.

[82] J. Dong, K. K. Sulik, and S. Y. Chen, "The role of NOX enzymes in ethanol-induced oxidative stress and apoptosis in mouse embryos," Toxicology letters, vol. 193, pp. 94-100, 2010.

[83] A. R. Patten, C. J. Fontaine, and B. R. Christie, "A comparison of the different animal models of fetal alcohol spectrum disorders and their use in studying complex behaviors," Frontiers in pediatrics, vol. 2, p. 93, 2014.

[84] X. Wang, Z. Ke, G. Chen et al., "Cdc42-dependent activation of NADPH oxidase is involved in ethanol-induced neuronal oxidative stress," PLoS One, vol. 7, article e38075, 2012.

[85] R. L. Pemathilaka, D. E. Reynolds, and N. N. Hashemi, "Drug transport across the human placenta: review of placenta-ona-chip and previous approaches," Interface Focus, vol. 9, p. 20190031, 2019.

[86] A. Schmidt, D. M. Morales-Prieto, J. Pastuschek, K. Fröhlich, and U. R. Markert, "Only humans have human placentas: molecular differences between mice and humans," Journal of Reproductive Immunology, vol. 108, pp. 65-71, 2015.

[87] C. V. Vorhees, J. N. Sprowles, S. L. Regan, and M. T. Williams, "A better approach to in vivo developmental neurotoxicity assessment: alignment of rodent testing with effects seen in children after neurotoxic exposures," Toxicology and applied pharmacology, vol. 354, pp. 176-190, 2018.

[88] M. Paparella, S. H. Bennekou, and A. Bal-Price, "An analysis of the limitations and uncertainties of in vivo developmental neurotoxicity testing and assessment to identify the potential for alternative approaches," Reproductive Toxicology, vol. 96, pp. 327-336, 2020.

[89] P. Brownbill, I. Chernyavsky, B. Bottalico et al., “An international network (PlaNet) to evaluate a human placental testing platform for chemicals safety testing in pregnancy," Reproductive Toxicology, vol. 64, pp. 191-202, 2016.

[90] D. Pamies, P. Barrera, K. Block et al., "A human brain microphysiological system derived from induced pluripotent stem cells to study neurological diseases and toxicity," Altex, vol. 34, pp. 362-376, 2017.

[91] A. Jorcano, M. J. Lubczyńska, L. Pierotti et al., "Prenatal and postnatal exposure to air pollution and emotional and aggressive symptoms in children from 8 European birth cohorts," Environment International, vol. 131, p. 104927, 2019.

[92] S. Kamata, R. Hashiyama, H. Hana-Ika et al., "Cytotoxicity comparison of 35 developmental neurotoxicants in human induced pluripotent stem cells (iPSC), iPSC-derived neural progenitor cells, and transformed cell lines," Toxicol In Vitro, vol. 69, p. 104999, 2020.

[93] A. Bal-Price, K. M. Crofton, M. Sachana et al., "Putative adverse outcome pathways relevant to neurotoxicity," Critical reviews in toxicology, vol. 45, pp. 83-91, 2015.

[94] F. Pistollato, D. Canovas-Jorda, D. Zagoura, and A. Bal-Price, "Nrf2 pathway activation upon rotenone treatment in human iPSC-derived neural stem cells undergoing differentiation towards neurons and astrocytes," Neurochemistry international, vol. 108, pp. 457-471, 2017.

[95] Y. Nishimura, S. Murakami, Y. Ashikawa et al., "Zebrafish as a systems toxicology model for developmental neurotoxicity testing," Congenital anomalies, vol. 55, pp. 1-16, 2015.
[96] J. Koiwa, T. Shiromizu, Y. Adachi et al., "Generation of a triple-transgenic zebrafish line for assessment of developmental neurotoxicity during neuronal differentiation," Pharmaceuticals, vol. 12, 2019.

[97] J. Corrales, L. A. Kristofco, W. B. Steele et al., "Toward the design of less hazardous chemicals: exploring comparative oxidative stress in two common animal models," Chemical research in toxicology, vol. 30, pp. 893-904, 2017.

[98] S. Sasagawa, Y. Nishimura, J. Koiwa et al., "In vivo detection of mitochondrial dysfunction induced by clinical drugs and disease-associated genes using a novel dye ZMJ214 in zebrafish," ACS chemical biology, vol. 11, pp. 381-388, 2015.

[99] K. Dale, J. D. Rasinger, K. L. Thorstensen, S. Penglase, and S. Ellingsen, "Vitamin E reduces endosulfan-induced toxic effects on morphology and behavior in early development of zebrafish (Danio rerio)," Food and chemical toxicology, vol. 101, pp. 84-93, 2017.

[100] C. Sakai, S. Ijaz, and E. J. Hoffman, "Zebrafish models of neurodevelopmental disorders: past, present, and future," Frontiers in molecular neuroscience, vol. 11, p. 294, 2018.

[101] F. Petrelli, L. Pucci, and P. Bezzi, "Astrocytes and microglia and their potential link with autism spectrum disorders," Frontiers in cellular neuroscience, vol. 10, p. 21, 2016.

[102] G. A. Dunn, J. T. Nigg, and E. L. Sullivan, "Neuroinflammation as a risk factor for attention deficit hyperactivity disorder," Pharmacology Biochemistry and Behavior, vol. 182, pp. 22-34, 2019.

[103] G. Bjørklund, A. A. Tinkov, B. Hosnedlová et al., “The role of glutathione redox imbalance in autism spectrum disorder: a review," Free Radical Biology and Medicine, vol. 160, pp. 149-162, 2020.

[104] G. Bjørklund, M. D. Doşa, M. Maes et al., "The impact of glutathione metabolism in autism spectrum disorder," Pharmacological Research, vol. 166, p. 105437, 2021.

[105] W. Y. Huang, S. Lin, H. Y. Chen et al., "NADPH oxidases as potential pharmacological targets against increased seizure susceptibility after systemic inflammation," Journal of neuroinflammation, vol. 15, p. 140, 2018.

[106] H. Y. Kuo and F. C. Liu, "Molecular pathology and pharmacological treatment of autism spectrum disorder-like phenotypes using rodent models," Frontiers in cellular neuroscience, vol. 12, p. 422, 2018.

[107] M. Krishnan and S. C. Kang, "Vitexin inhibits acrylamideinduced neuroinflammation and improves behavioral changes in zebrafish larvae," Neurotoxicology and teratology, vol. 74, p. 106811, 2019.

[108] B. C. Freitas, P. C. B. Beltrão-Braga, and M. C. Marchetto, "Modeling inflammation on neurodevelopmental disorders using pluripotent stem cells," Advances in Neurobiology, vol. 25, pp. 207-218, 2020.

[109] R. Nagano, H. Akanuma, X. Y. Qin et al., "Multi-parametric profiling network based on gene expression and phenotype data: a novel approach to developmental neurotoxicity testing," International journal of molecular sciences, vol. 13, pp. 187-207, 2012.

[110] K. Oh-Hashi, A. Sone, T. Hikiji et al., "Transcriptional and post-transcriptional regulation of transmembrane protein 132A," Molecular and cellular biochemistry, vol. 405, pp. 291-299, 2015.

[111] Y. Zeng, Y. Kurokawa, T. T. Win-Shwe et al., "Effects of PAMAM dendrimers with various surface functional groups 
and multiple generations on cytotoxicity and neuronal differentiation using human neural progenitor cells," The Journal of toxicological sciences, vol. 41, pp. 351-370, 2016.

[112] J. Yamane, S. Aburatani, S. Imanishi et al., "Prediction of developmental chemical toxicity based on gene networks of human embryonic stem cells," Nucleic Acids Research, vol. 44, pp. 5515-5528, 2016.

[113] S. Sasagawa, Y. Nishimura, T. Kon et al., "DNA damage response is involved in the developmental toxicity of mebendazole in zebrafish retina," Frontiers in pharmacology, vol. 7, p. $57,2016$.

[114] S. Halappanavar, S. Van Den Brule, P. Nymark et al., "Adverse outcome pathways as a tool for the design of testing strategies to support the safety assessment of emerging advanced materials at the nanoscale," Particle and Fibre Toxicology, vol. 17, p. 16, 2020.

[115] P. Nymark, P. Kohonen, V. Hongisto, and R. C. Grafström, "Toxic and genomic influences of inhaled nanomaterials as a basis for predicting adverse outcome," Annals of the American Thoracic Society, vol. 15, pp. S91-S97, 2018.

[116] A. Rădulescu and S. Lundgren, "A pharmacokinetic model of lead absorption and calcium competitive dynamics," Scientific reports, vol. 9, p. 14225, 2019.

[117] N. I. Markevich and J. B. Hoek, "Computational modeling analysis of mitochondrial superoxide production under varying substrate conditions and upon inhibition of different segments of the electron transport chain," Biochimica et Biophysica Acta (BBA)-Bioenergetics, vol. 1847, pp. 656-679, 2015.

[118] E. J. Pereira, C. M. Smolko, and K. A. Janes, "Computational models of reactive oxygen species as metabolic byproducts and signal-transduction modulators," Frontiers in pharmacology, vol. 7, p. 457, 2016.

[119] S. Zhang, W. A. Khan, L. Su et al., "Predicting oxidative stress induced by organic chemicals by using quantitative structure-activity relationship methods," Ecotoxicology and Environmental Safety, vol. 201, p. 110817, 2020.

[120] S. Fragki, A. H. Piersma, E. Rorije, and M. J. Zeilmaker, "In vitro to in vivo extrapolation of effective dosimetry in developmental toxicity testing: application of a generic PBK modelling approach," Toxicology and applied pharmacology, vol. 332, pp. 109-120, 2017.

[121] E. Di Consiglio, F. Pistollato, E. Mendoza-De Gyves, A. Bal-Price, and E. Testai, "Integrating biokinetics and in vitro studies to evaluate developmental neurotoxicity induced by chlorpyrifos in human iPSC-derived neural stem cells undergoing differentiation towards neuronal and glial cells," Reproductive Toxicology, vol. 98, pp. 174-188, 2020.

[122] F. Troger, J. Delp, M. Funke et al., "Identification of mitochondrial toxicants by combined in silico and in vitro studies - a structure-based view on the adverse outcome pathway," Computational Toxicology, vol. 14, p. 100123, 2020.

[123] J. Hemmerich, F. Troger, B. Füzi, and G. F. Ecker, "Using machine learning methods and structural alerts for prediction of mitochondrial toxicity," Molecular Informatics, vol. 39, p. 2000005, 2020. 